Research Article

\title{
PCR-Based Direct Detection of Streptococcus uberis from Subclinical and Clinical Dairy Cattle Milk Samples
}

\author{
Virginia E. Sherwin (D), Morena Santi $(\mathbb{D}$, Olivia Walker $(\mathbb{D}$, Natalie D. Pickwell (D), \\ Tracey J. Coffey $\mathbb{D}$, James A. Leigh $\mathbb{D}$, and Sharon A. Egan $\mathbb{1}$
}

\begin{abstract}
The School of Veterinary Medicine and Science, University of Nottingham, Sutton Bonington Campus, Sutton Bonington,
\end{abstract} Leicestershire LE12 5RD, UK2811

Correspondence should be addressed to Sharon A. Egan; sharon.egan@nottingham.ac.uk

Received 15 May 2020; Revised 20 November 2020; Accepted 25 November 2020; Published 8 December 2020

Academic Editor: Juan G. Chediack

\begin{abstract}
Copyright (c) 2020 Virginia E. Sherwin et al. This is an open access article distributed under the Creative Commons Attribution License, which permits unrestricted use, distribution, and reproduction in any medium, provided the original work is properly cited.

Streptococcus uberis is one of the leading causes worldwide of mastitis in the dairy industry, with the most likely sources of infection attributed to environmental reservoirs such as contaminated bedding materials. Early detection of those cases most likely to progress to clinical disease would lead to improved animal welfare, a critical component of overall health and productivity. A multiplex PCR-based diagnostic test was developed for detection of S. uberis directly from milk and targeting two genes previously identified as important for intramammary colonisation and persistence in dairy cattle. Results indicated the threshold for detection directly from milk was $20,000 \mathrm{CFU} / \mathrm{ml}$ and this was achieved without the need for preenrichment. In addition, $S$. uberis could be identified from milk samples collected during intramammary challenge studies, prior to clinical signs of infection and at much lower detection limits. The PCR test developed for confirmation of the presence of $S$. uberis directly from infected milk has potential value as a diagnostic test to identify early infection and/or to confirm that antibiotic therapy has been successful.
\end{abstract}

\section{Introduction}

Bovine mastitis is one of the most prevalent diseases within the dairy industry, resulting in significant economic and production losses, and is a considerable welfare issue for affected cows [1-3]. The current rate of clinical mastitis in the UK has been reported at 47 cases per 100 cows per year [4] with associated costs estimated to vary between $£ 110$ and $£ 340$ per cow [5-8]. There are an estimated 2.73 million dairy cows in the UK [9], and therefore approximately 1.28 million cases of clinical mastitis with financial losses attributed to vary between $£ 141$ and $£ 436$ million per annum in the UK alone. Confirmation of intramammary infection and early treatment of these animals are critical for reducing production costs and improving overall animal welfare. Treatment is most often initiated once clinical signs are apparent, with observed changes in the appearance, composition, and yield of milk and inflammation of the udder common [1]. It is estimated that, for control of intramammary infections in the UK dairy industry alone, 4 million tonnes of active ingredient is used each year [10]. Given the increasing threat of antimicrobial resistance [10], early diagnosis and targeted therapy for intramammary pathogens are critical, alongside monitoring treatment efficacy.

Streptococcus uberis (S. uberis) is an opportunistic, environmental dairy pathogen, responsible for $23 \%$ of clinical mastitis cases in the UK [4], with similar rates seen worldwide. It is ubiquitous within the dairy cow's environment and has been isolated from in and on the dairy cow, including the skin, rumen, genitourinary tract and faeces, bedding, and pasture [11-14]. Clinical mastitis due to S. uberis typically corresponds with high bacterial numbers between $10^{6}$ and $10^{8} \mathrm{cfu} / \mathrm{ml}$ of milk $[15,16]$ although bacterial concentrations may peak as high as $10^{9} \mathrm{cfu} / \mathrm{ml}$. Chronic subclinical infection has been attributed to $S$. uberis where it may act as a contagious source of the pathogen $[17,18]$. Confirmation of $S$. uberis as the causative bacterial 
agent forms an integral part herd management for mastitis control and this can influence antimicrobial therapy choices for treatment and whether drying off or culling may be required. In the majority of on-farm cases, animals are treated with broad-spectrum antibiotics upon signs of clinical infection, with no specific determination of the species responsible.

The accepted "gold standard" for diagnosis of S. uberis infection is following direct culture of milk on blood aesculin plates, with identification in most clinical laboratories utilising biochemical testing or API-based strip tests or enzymatic profiling [19]. Whilst advantages include the detection of viable bacteria, and the relatively inexpensive nature of culture based diagnostics, characterization based on phenotypic markers can be unreliable due to a lack of unique biochemical markers present among mastitis pathogens, including streptococcal and enterococcal species [20-23]. The time taken for culture-based confirmation, typically 2-3 days after recognition of clinical signs of infection, alongside problems with nonculturable organisms from milk samples means that this diagnostic approach is undersubscribed for infection management [4, 24].

The use of DNA-based diagnostic tests can allow rapid screening of large numbers of samples and have the potential to be extremely specific and allow distinction of closely related organisms, given careful design of the target sequence. They have also been previously used to detect bacteria in clinical samples which failed to grow in culture, as they are not dependent on the presence of viable bacteria within samples $[22,25,26]$. PCR-based assays confer an advantage of rapid turnaround time and can eliminate the subjectivity of assay interpretation, with sensitivity of PCR greater than traditional culture-based methods $[27,28]$. Several studies have evaluated PCR for detection of S. uberis; however, specificity and sensitivity are often lower in comparison with other common mastitis pathogens and may reflect the choice of genomic target for the diagnostic PCR tests that have been previously developed [22, 26, 28-30]. Food products such as milk also contain PCR inhibitors including fat, protein, and calcium, and DNA extraction prior to testing is often key for a successful diagnostic outcome [31, 32]. Bacterial DNA can be readily extracted using organic solvents such as phenolchloroform or using salt precipitation to remove such contaminants, providing a relatively cheap and cost-effective method for DNA isolation in comparison with commercially available kits [33, 34].

Here, we describe the evaluation of a multiplex PCRbased test for identification of S. uberis directly from milk, utilising highly conserved gene targets. The ability to detect the presence of $S$. uberis at levels below those associated with clinical mastitis indicated the potential use of this assay for early detection of infection or confirmation of successful therapeutic treatment.

\section{Materials and Methods}

2.1. Bacterial Strains and Reagents. S. uberis strain 0140 J (strain ATCC BAA-854/0140 J), originally isolated from a clinical case of bovine mastitis in the UK, and 12 other previously characterised clinical strains [35] were used throughout this study. The Escherichia coli strain P4 and Staphylococcus aureus strain M60 were both similarly isolated from clinical cases of bovine mastitis [36, 37]. S. agalactiae stains $0247 \mathrm{a}$ and 0251 and S. dysgalactiae 0154 and A1 were obtained from historical cases of mastitis in the UK. L. garvieae 131016 was isolated from a case of clinical mastitis in the UK and provided by Professor A Bradley (University of Nottingham). E. faecium 7831 was provided by Professor P. Barrow (University of Nottingham). S. pneumoniae TIGR4 [38] was included as a nonmastitis pathogen control. A total of 32 mastitic milk samples were collected from a 230-dairy-cow herd in Leicestershire, UK, with a history of environmental mastitis and identified through national milk record (NMR) testing. Milk samples were cultured on sheep blood agar containing $1 \%(\mathrm{w} / \mathrm{v})$ aesculin (Cherwell Laboratories). All bacterial strains were confirmed to be the correct species by $16 \mathrm{~S}$ rDNA-based sequencing. Bacteria were routinely grown in Todd Hewitt (THB) or Brain Heart Infusion (BHI) broth (Oxoid Ltd, UK) at $37^{\circ} \mathrm{C}$.

2.2. DNA Extraction. S. uberis $0140 \mathrm{~J}$ was spiked into $1 \mathrm{ml}$ of whole milk and serially diluted $1: 10$, to provide a total of 9 spiked milk samples and 1 milk-only control. Three DNA extraction methods were evaluated to compare their relative efficiency with respect to the extraction of S. uberis DNA from milk: an in house phenol: chloroform based extraction, the PowerFood Microbial DNA Isolation kit (Qiagen) and QuickExtract DNA extraction solution (Epicentre). The phenol extraction protocol was performed as previously described [15]; however, bacterial cell walls were disrupted with cell disruption buffer containing 60 units/mL mutanolysin and $20 \mathrm{mg} / \mathrm{mL}$ lysozyme (both from Sigma-Aldrich, $\mathrm{UK})$ and total cell lysis was achieved using $50 \mu \mathrm{L}$ of SDS solution $(20 \% \mathrm{w} / \mathrm{v}$ in $50 \mathrm{mM}$ Tris-Cl, $20 \mathrm{mM}$ EDTA, pH 7.8) and $200 \mu \mathrm{g} / \mathrm{mL}$ proteinase $\mathrm{K}$ (Sigma). Isolation of DNA using the Power Food Microbial DNA Isolation kit was performed as per manufacturers' instructions, using the alternative lysis method when there is difficulty in lysing cells. Isolation of DNA using the QuickExtract DNA solution was performed after centrifugation of samples at $13,000 \times \mathrm{g}$ for $5 \mathrm{~min}$ and resuspension of the resulting pellet in $500 \mu \mathrm{L}$ of QuickExtract solution. The solution was vortexed for $15 \mathrm{sec}$, heated at $65^{\circ} \mathrm{C}$ for $15 \mathrm{~min}$, vortexed for $15 \mathrm{sec}$ then heated at $98^{\circ} \mathrm{C}$ for 2 min as per manufacturer's instructions, and stored at $-20^{\circ} \mathrm{C}$ prior to use. All other bacterial DNA samples were generated from $1.5 \mathrm{ml}$ of overnight culture using the standard phenol:chloroform extraction protocol previously described [15].

\subsection{Primer Design for Identification of sub0888 and sub1154.} Primers were designed to amplify conserved regions of sub0888 and sub1154, both previously identified as unique to S. uberis [39] and, in the case of sub1154, essential clinical mastitis following experimental challenge [15]. Sequences were analysed for conservation and identity within the NCBI nonredundant nucleotide basic local alignment database 
[40] and the S. uberis MLST database (https://pubmlst.org/ suberis/) [41, 42].

2.4. PCR Amplification of Target Genes. PCR amplification of $16 \mathrm{~S}$ rDNA was performed using Streptococcus specific primers (Table 1) [43] and GoTaq Green Master Mix (Promega) containing $0.5 \mu \mathrm{M}$ of each primer and approx. $5 \mathrm{ng}$ of DNA template. PCR amplification was performed using a LifeEco thermal cycler (BioER) with amplification programme consisting of an initial denaturation step at $95^{\circ} \mathrm{C}$ for $2 \mathrm{~min}$, followed by 30 cycles, denaturation at $95^{\circ} \mathrm{C}$ for $20 \mathrm{sec}$, annealing at $60^{\circ} \mathrm{C}$ for $30 \mathrm{sec}$, and extension at $72^{\circ} \mathrm{C}$ for $45 \mathrm{sec}$ with a final elongation step at $72^{\circ} \mathrm{C}$ for $5 \mathrm{~min}$. PCR amplification of sub0888 and sub1154 was performed using GoTaq Green Master Mix (Promega) as above, using primer concentrations of $0.5 \mu \mathrm{M}$ for P1100 and 1101 and $0.25 \mu \mathrm{M}$ for P1102 and 1103 (Table 1) and an annealing temperature of $61^{\circ} \mathrm{C}$. Quality and quantity of the PCR product were assessed following separation by $1 \%$ agarose gel electrophoresis and PCR products were purified using MinElute gel extraction (Qiagen) according to manufacturer's instructions. Quantification was performed using Qubit ${ }^{\mathrm{TM}} \mathrm{dsDNA}$ BR assays (Thermo Fisher) and sequencing of the purified product was performed by Source Biosciences using P665 as the sequencing primer.

2.5. Cattle Challenge Experiments. Frozen milk samples from previous dairy challenge experiments $[15,44]$ conducted at IAH, Compton Laboratory under PPL 30/2645, were used in this study to determine the detection limits for S. uberis $0140 \mathrm{~J}$ within milk. Briefly, 4 Holstein-Friesian cows, 2-10 weeks into their first lactation with no previous history of mastitis, were challenged with approximately $1000 \mathrm{cfu} / \mathrm{ml}$ of S. uberis $0140 \mathrm{~J}$ in two contralateral quarters. Animals were milked and inspected twice daily $(07: 00 \mathrm{~h}$ and $15: 30 \mathrm{~h})$ and treated with appropriate antibiotics once clinical end points had been reached using criteria previously described [15, 45] and clinical scores recorded for changes in milk and udder quarters. Milk samples were taken at each milking and analysed for the presence of bacteria and somatic cells, with viable bacteria estimated by direct plating of each milk sample onto aesculin blood agar plates.

\section{Results}

3.1. Generation of sub0888 and sub1154 PCR Primers for Identification of S. uberis. Primers were designed to amplify a conserved region of DNA, $222 \mathrm{bp}$ upstream and then internal to sub0888 of S. uberis $0140 \mathrm{~J}$ to produce a product of $974 \mathrm{bp}$. Primer sequences showed $100 \%$ identity with sequences in 3 additional completed S. uberis genome sequences (NCTC4674, NCTC3858, and NZ01) and 12 partially completed genomes [35]. Additionally, the sense primer P1100 showed 100\% identity to all strains within the S. uberis BIGSdb database and the antisense primer $82 \%$ identity, with a single base mismatch identified within the remaining strains at position $15(\mathrm{G}: \mathrm{A})$ for 21 strains and position 9 (T:A) for a further 2 strains. Of the total 132 strains in the MLST database, one gene sequence was truncated for sub0888 and this sequence was incomplete. Primers designed to amplify an internal conserved region of sub1154 produced a product of $573 \mathrm{bp}$ and showed $100 \%$ identity to all known S. uberis sequences on both the NCBI and MLST databases.

3.2. Comparison of Multiplex Primers for S. uberis Detection. Genomic DNA was extracted from 12 strains of S. uberis and presence of sub0888 and sub1154 confirmed by multiplex PCR (Figure 1(a)). In addition, the multiplex PCR was performed using genomic DNA from a number of bacterial pathogens previously associated with mastitis including E. coli, S. aureus, S. agalactiae, S. dysgalactiae, and L. garvieae and a number of related species from the Streptococcaceae family (E. faecium and S. pneumoniae), all of which were negative (Figure 1(b)), with $16 S$ rDNA PCR performed to confirm the presence of genomic DNA in these samples (Figure 1(c)).

3.3. Comparison of DNA Extraction Methods from Milk for S. uberis Detection. Whole milk $(1 \mathrm{ml})$ was inoculated with approx. $2 \times 10^{8}$ cfu of $S$. uberis and serially diluted 10 -fold to a concentration equivalent to $\sim 2 \mathrm{cfu} / \mathrm{ml}$. DNA was extracted from the samples using either an in-house phenol: chloroform extraction method, the PowerFood Microbial DNA Isolation kit (Qiagen), or the QuickExtract DNA Extraction solution (Epicentre). Each PCR was performed using $1 \mu \mathrm{L}$ of extracted DNA using the GoTaq G2 Hot Start Green Master Mix. Bacteria were detected at a concentration of $2 \times 10^{6} \mathrm{cfu} / \mathrm{ml}$ in spiked milk processed using the PowerFood Microbial DNA Isolation kit and $2 \times 10^{4} \mathrm{cfu} / \mathrm{ml}$ in milk processed using the phenol:chloroform extracted DNA (Figure 2). No amplification of DNA was detected in samples that were extracted using the QuickExtract DNA extraction solution. In addition, DNA was unable to be amplified using either Standard Taq (with ThermoPol buffer) or Phusion polymerases (NEB) (data not shown) using DNA isolated from the spiked milk samples.

3.4. Recovery and Confirmation of S. uberis Strain Type from Clinical Mastitis Samples. Frozen milk samples $(n=32)$ were provided by a local Leicestershire farm, with a history of environmental clinical mastitis. Milk samples were thawed and plated onto ABA plates, with single colonies selected for growth and DNA extraction. Bacterial identity was confirmed for $50 \%$ of the samples by $16 \mathrm{~S}$ rDNA-based sequencing which identified 13 as S. uberis, 2 as Staphylococcus sciuri, and 1 as Bacillus licheniformis. Each milk sample $(1 \mathrm{ml})$ was processed to obtain DNA using the phenol: chloroform extraction method and 14 samples were identified as positive for S. uberis based on the multiplex PCR (Figure 3), including all those identified as S. uberis by $16 \mathrm{~S}$ rDNA sequencing. One additional milk sample was found to be positive by PCR and bacterial culture was unable to be obtained from this sample. 
TABLE 1: Oligonucleotide primer sequences used in this study.

\begin{tabular}{lcccc}
\hline Designation & Target & Primer sequence & Product size & Annealing temp $\left({ }^{\circ} \mathrm{C}\right)$ \\
\hline $665 \mathrm{Fwd}$ & 16 S rRNA & $5^{\prime}$-GAGAGTTTGATCCTGGCTCAGGA-3' & $529 \mathrm{bp}$ & \\
$666 \mathrm{rev}$ & 16 S rRNA & $5^{\prime}$-TTACCGCGGCTGCTGGCACGT-3' & & \\
$1100 \mathrm{Fwd}$ & S. uberis sub0888 & 5'-CTTTATGAAAATAGCCAAGCTGAAA-3' $^{\prime}$ & $974 \mathrm{bp}$ & \\
$1101 \mathrm{rev}$ & S. uberis sub0888 & $5^{\prime}$-TGTGAGCCAGTTGGAGGAAG-3' & & \\
$1102 \mathrm{Fwd}$ & S. uberis sub1154 & $5^{\prime}$-ACAAAGTTGAAAAGGGGCGT-3' & $573 \mathrm{bp}$ & 61 \\
$1103 \mathrm{rev}$ & S. uberis sub1154 & $5^{\prime}$-CGCCATTAGGTGAAAGTGCT-3' & \\
\hline
\end{tabular}

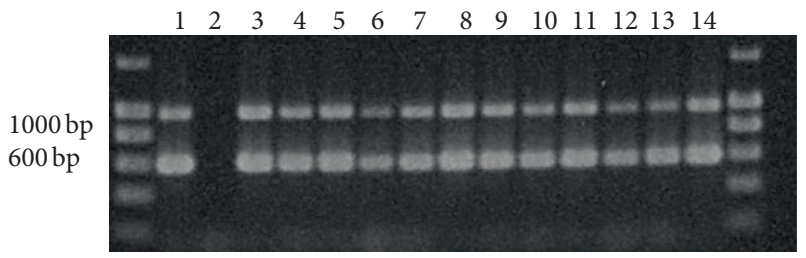

(a)

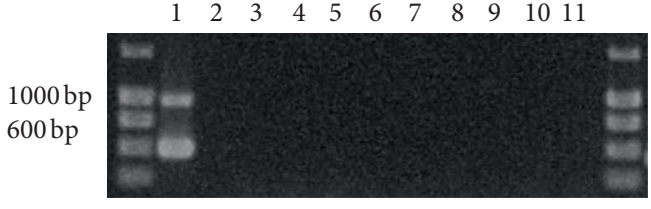

(b)

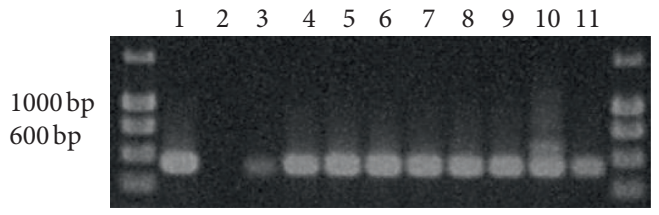

(c)

FiguRe 1: Multiplex PCR for S. uberis detection. (a) Detection of sub0888 and sub1154 in S. uberis strains EF20, 6736, 6780, Ab71, B190, B362, C5072, C5388, C6344, C8329, C9359, S6261 (lanes 3-14), S. uberis 0140 J and no template control in lanes 1 and 2, respectively. (b) Detection of sub0888 and sub1154 in other bacterial strains, E. coli P4, S. aureus M60, S. agalactiae 0247a and 0251, S. dysgalactiae 0154 and A1, L. garvieae 131016 (isolated from cases of clinical mastitis), E. faecium and S. pneumoniae TIGR4 in lanes 3-11, respectively, S. uberis $0140 \mathrm{~J}$ and no template control in lanes 1 and 2, respectively. (c) Confirmation of presence of $16 \mathrm{~s} \mathrm{rRNA}$ in other bacterial strains, as analysed in Figure 1(b).

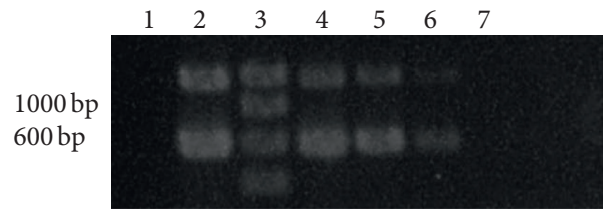

(a)

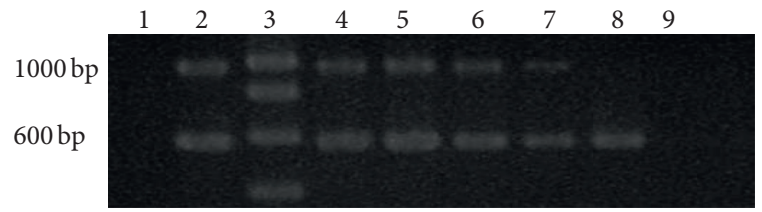

(b)

Figure 2: Comparison of DNA extraction methods from milk. Detection of sub0888 and sub1154 in S. uberis $0140 \mathrm{~J}$ spiked milk from (a) PowerFood Microbial DNA Isolation kit detected to a level of $2 \times 10^{6} \mathrm{cfu} / \mathrm{ml}$ and (b) phenol: chloroform extraction detected to a level of $2 \times 10^{4} \mathrm{cfu} / \mathrm{ml}$.

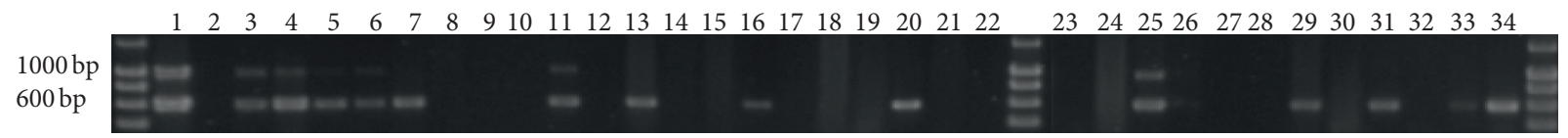

Figure 3: Multiplex PCR analysis for clinical mastitic milk samples. Detection of sub0888 and sub1154 directly from mastitic milk samples with 14 of 32 samples identified as positive. Smearing correlated with samples that had large cell pellets, most likely due to high numbers of somatic cells within the samples. S. uberis $0140 \mathrm{~J}$ positive control and negative control are in lanes 1 and 2, respectively.

3.5. Recovery of S. uberis $0140 \mathrm{~J}$ as Assessed by PCR from Experimental Challenge Samples. DNA was extracted from $1 \mathrm{ml}$ of milk using the phenol: chloroform extraction method from quarter milk samples obtained from 4 cattle challenged in two contralateral quarters with $S$. uberis $0140 \mathrm{~J}[15,44]$. S. uberis was detected by multiplex PCR in $75 \%$ of samples obtained after 16 hours of challenge and $100 \%$ after 24 hours of challenge (Figure 4(a)). This corresponded with a bacterial concentration of greater than $1000 \mathrm{cfu} /$ per $\mathrm{ml}$ of milk. Bacterial presence was confirmed to occur prior to observation of clinical signs (Figure 4(b)), as outlined in previous studies [45]. 


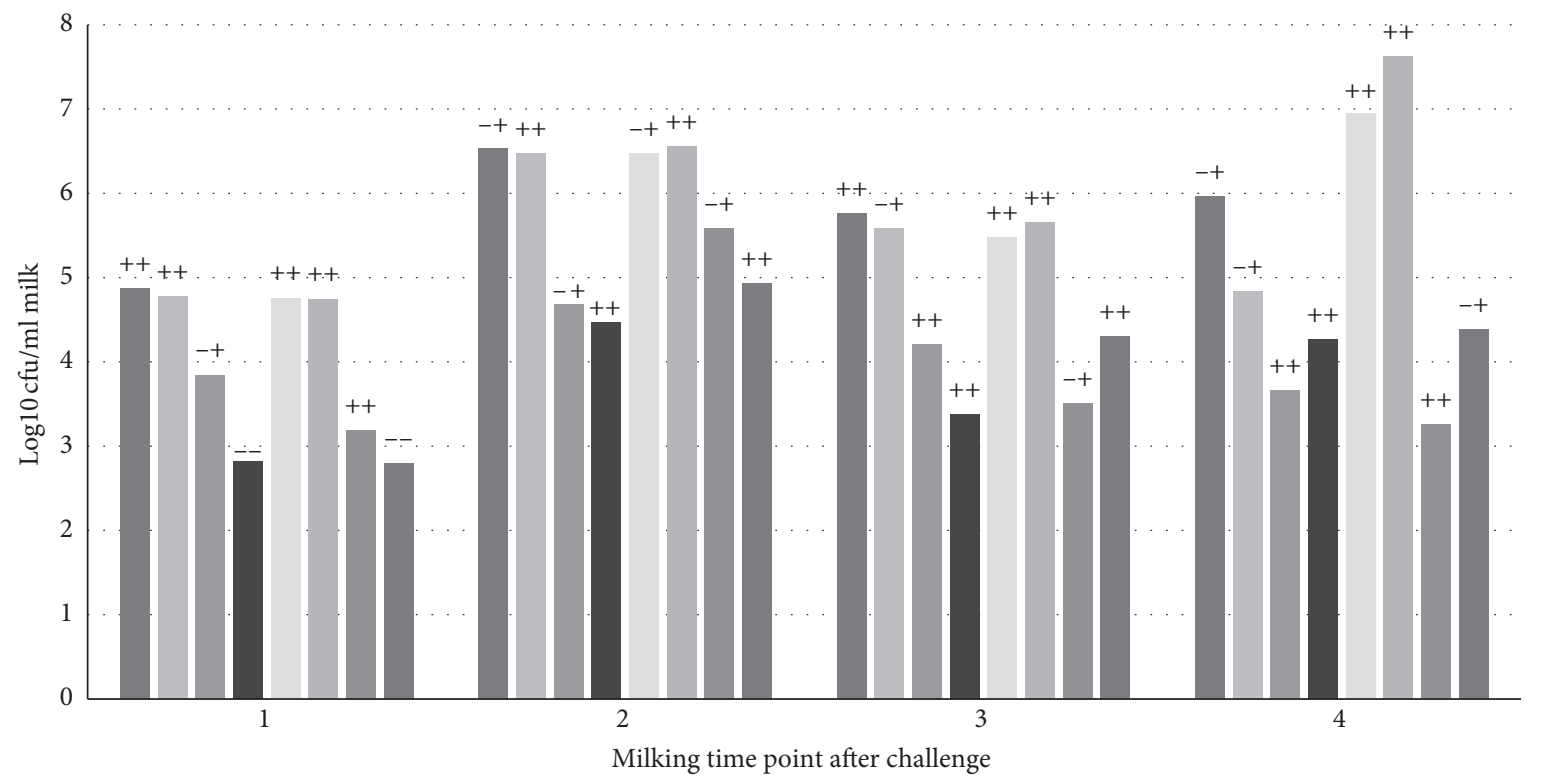

- Cow \#7303 RF

- Cow \#7303 LH

- Cow \#7314 RH

- Cow \#7314 LF

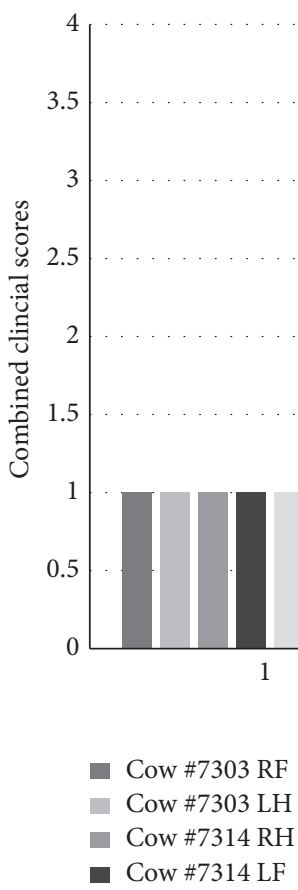

Cow \#7493 RH

- Cow \#7493 LF

- Cow \#8199 RH

- Cow \#8199 LF

(a) 


\section{Discussion}

The successful implementation of the "Five-Point Plan" [46] has significantly reduced the rates of clinical mastitis associated with contagious bacterial pathogens Staphylococcus aureus and Streptococcus agalactiae. Given the difficulty in controlling environmental mastitis pathogens particularly those identified within the faecal microbiota such as E. coli and S. uberis, it is not surprising that rates of clinical mastitis associated with these pathogens have continued to rise $[4,47]$. Management practices should also include environmental management of pasture, bedding, and housing to minimise faecal contamination risks. In addition, the development of rapid, low-cost, species-specific diagnostic tests for targeted antimicrobial therapy is pivotal for identifying early clinical cases of $S$. uberis infection and to confirm that antibiotic therapy has been successful. This study focused on the development of a multiplex PCR diagnostic test for the detection of $S$. uberis DNA directly from milk samples, using highly conserved genomic sequences, and was able to confirm the presence of S. uberis within milk obtained from naturally and experimentally infected animals.

PCR-based assays have been investigated as an alternative to traditional culture-based methods, for a many different mastitis pathogens, including S. uberis. Primarily, this is due to the rapid results that can be obtained in comparison to culture-based assessment and subsequent biochemical testing, which generally takes $2-3$ days to yield a specific bacterial identification. An additional benefit is that identification of nonculturable organisms can be achieved, particularly important for subclinical mastitis samples when bacterial numbers may fluctuate [4, 24]. Studies have evaluated PCR as a viable method for $S$. uberis detection, each with variable gene target choices, where target information has not been specified [22, 26, 28-30], or have focused on amplification of specific $16 \mathrm{~S}$ and $23 \mathrm{~S}$ rDNA regions, which in some cases made differentiation of amplified products difficult in post-PCR analysis [22, 23, 31].

Given the rapid increase in available genome sequences for comparative analysis of bacterial isolates, primers in this study were designed to target sub0888 and sub1154 of S. uberis, both previously identified as sortase anchored, surface anchored proteins [48]. It was decided to use sub0888 as a target as it has been identified to share no known homology with genes in any other bacterial genome and appears to be unique to $S$. uberis. The second target, sub1154, shows very low $(<30 \%)$ identity to the C5a peptidase of $S$. pyogenes and a number of other streptococcal proteins $[39,48]$. The resulting protein is essential for early colonisation of the udder and subsequent infection during clinical mastitis [15]. The specific primer sequences used in this study were selected to conserve DNA sequences present, known to be present in all annotated S. uberis genomes, present on NCBI genome databases [40]. Further analysis of sequence conservation was conducted on sequences present in S. uberis MLST database, with $100 \%$ identity for the sub1154 primers and for the sub0888 primers and $99.2 \%$ identity when allowing for a 1 base pair mismatch $[49,50]$, and would therefore provide high specificity for $S$. uberis within the PCR assay. The $S$. uberis strains within both databases include clinical and subclinical isolates from the UK, Canada, and New Zealand and it is reasonable that this would be similar for other strains isolated around the world. Given the sequence conservation of the primers used in the multiplex PCR, it was not surprising that amplification using DNA extracted from bacterial culture successfully amplified both genes in a range of $S$. uberis strains (Figure 1(a)) and additionally did not result in amplification of products from a range of related streptococci or mastitis-related pathogens (Figure 1(b)).

Whilst a number of PCR-based tests have been assessed including the PathoProof diagnostic test, which tests for the 12 main causative pathogens associated with mastitis, lower sensitivity and specificity for $S$. uberis detection have been reported compared with other mastitis pathogens such as S. aureus [28]. This may also be related to difficulty in extracting high-quality DNA from some Gram-positive bacteria, in particular when using commercially available DNA extraction kits and isolation directly from milk [31, 51] or variability in the target genomic sequence selected for PCR analysis. For any PCR-based analysis, the quality of the DNA and removal of any inhibitory components which may be present in milk is critical for reproducibility of the assay. Numerous methods for extracting bacterial DNA directly from milk have been reported in literature including the use commercially available kits such as the bacterial DNA isolation kit from Norgen Biotek and the DNeasy PowerFood Microbial Kit from Qiagen, magnetic beads to bind DNA, alkaline or detergent extraction [52], pronase [30], and phenol-chloroform based extraction [53]. Comparative studies indicated the Qiagen DNeasy PowerFood microbial kit and Novogen Milk Bacterial Isolation kit could provide high yields of Gram-positive bacterial DNA; however, PowerFood kit was superior for DNA purity $[51,54]$. This kit was selected for comparison, alongside an in-house, phenolchloroform based method [55]. A key component of the inhouse lysis method utilises the enzyme mutanolysin from Streptomyces globisporus which has been found to be superior for lysis of some Gram-positive bacterial species, particularly streptococci, in comparison to other enzymes such as lysozyme $[56,57]$. In this study, phenol-chloroformbased exaction was superior to that of the commercial kit and could detect $S$. uberis at a lower limit of $1 \times 10^{4} \mathrm{cfu} / \mathrm{mL}$ in spiked milk studies (Figure 2) and supports previous studies which reported to be a successful mechanism for removal of inhibitory substances for downstream PCR-based applications [58]. Similar detection limits were observed when tested on milk samples from experimentally challenged animals (Figure 4), and these could confirm the presence of S. uberis prior to observation of clinical changes in milk or udder.

Whilst detection at levels of between $10^{4}$ and $10^{5} \mathrm{cfu} / \mathrm{ml}$ may seem relatively high compared to some of the more sensitive RT-PCR methods, previous experimental challenge studies have indicated that this bacterial concentration in milk results in a "tipping point" where animals are highly likely to progress to clinical mastitis requiring antibiotic 
therapy $[15,44,45,59]$. Given this, detection of $S$. uberis at a level lower than $1000 \mathrm{cfu} / \mathrm{ml}$ may not be clinically relevant and result in overtreatment of animals unlikely to progress to clinical disease. One surprising aspect was the different performance of the primers on DNA extracted from clinical samples, in particular when the bacterial cell counts were between $1 \times 10^{4}$ and $1 \times 10^{5} \mathrm{cfu} / \mathrm{ml}$. In these cases the sub1154 primers performed more reliably than the $s u b 0888$ primers, potentially due to the smaller product produced in the assay as the primer melting temperature for both primers was similar. The highly conserved nature of both sub0888 and sub1154 within isolates indicates that each target could be suitable for future qRT-PCR development; however, the likely increased sensitivity would need to be balanced, given that detection of low numbers of $S$. uberis may not correlate to progression to clinical mastitis.

Overall, this DNA extraction and PCR application for detection of $S$. uberis directly from milk provides a reproducible method for diagnosis of cattle likely to progress to clinical mastitis, using highly specific gene targets. The implementation of such a diagnostic could form part of a herd management strategy, to identify cases of infection most likely to progress to clinical mastitis, before the absence of overt clinical signs. In addition, it could be used to confirm successful antibiotic therapy for S. uberis mastitis, leading to improved animal health, welfare, and therapeutic outcome.

\section{Data Availability}

Data associated with this manuscript are available upon request to Dr. Sharon Egan.

\section{Conflicts of Interest}

The authors declare that they have no conflicts of interest.

\section{Acknowledgments}

This research was jointly funded by the Barham Benevolent Foundation and the School of Veterinary Medicine and Science, University of Nottingham.

\section{References}

[1] M. J. Green, Dairy Herd Health, CAB International, Wallingford, UK, 2012.

[2] T. Halasa, K. Huijps, O. Østerås, and H. Hogeveen, "Economic effects of bovine mastitis and mastitis management: a review," Veterinary Quarterly, vol. 29, no. 1, pp. 18-31, 2007.

[3] P. L. Ruegg, "A 100-Year Review: mastitis detection, management, and prevention," Journal of Dairy Science, vol. 100, no. 12, pp. 10381-10397, 2017.

[4] A. J. Bradley, K. A. Leach, J. E. Breen, L. E. Green, and M. J. Green, "Survey of the incidence and aetiology of mastitis on dairy farms in England and Wales," Veterinary Record, vol. 160, no. 8, pp. 253-258, 2007.

[5] D. Bar, L. W. Tauer, G. Bennett et al., "The cost of generic clinical mastitis in dairy cows as estimated by using dynamic programming," Journal of Dairy Science, vol. 91, no. 6, pp. 2205-2214, 2008.
[6] P. M. Down, M. J. Green, and C. D. Hudson, "Rate of transmission: a major determinant of the cost of clinical mastitis," Journal of Dairy Science, vol. 96, no. 10, pp. 6301-6314, 2013.

[7] C. Hagnestam-Nielsen and S. Østergaard, "Economic impact of clinical mastitis in a dairy herd assessed by stochastic simulation using different methods to model yield losses," Animal, vol. 3, no. 2, pp. 315-328, 2009.

[8] E. Rollin, K. C. Dhuyvetter, and M. W. Overton, "The cost of clinical mastitis in the first 30 days of lactation: an economic modeling tool," Preventive Veterinary Medicine, vol. 122, no. 3, pp. 257-264, 2015.

[9] AHDB, UK and EU Cow Numbers, AHDB, Kenilworth, UK, 2019, https://ahdb.org.uk/dairy/uk-and-eu-cow-numbers.

[10] UK-VARRS, Veterinary Antimicrobial Resistance and Sales Surveillance 2018, Veterinary Medicines Directorate, New Haw, Addlestone, 2019, https://www.gov.uk/government/ publications/veterinary-antimicrobial-resistance-and-salessurveillance-2018.

[11] A. J. Bramley, "Sources of streptococcus uberisin the dairy herd: i. Isolation from bovine faces and from straw bedding of cattle," Journal of Dairy Research, vol. 49, no. 3, pp. 369-373, 1982.

[12] J. Kruze and A. J. Bramley, "Sources of Streptococcus uberis in the dairy herd: II. Evidence of colonization of the bovine intestine by Str. uberis," Journal of Dairy Research, vol. 49, no. 3, pp. 375-379, 1982.

[13] M. G. Lopez-Benavides, J. H. Williamson, G. D. Pullinger, S. J. Lacy-Hulbert, R. T. Cursons, and J. A. Leigh, "Field observations on the variation of streptococcus uberis populations in a pasture-based dairy farm," Journal of Dairy Science, vol. 90, no. 12, pp. 5558-5566, 2007.

[14] R. N. Zadoks, L. L. Tikofsky, and K. J. Boor, "Ribotyping of Streptococcus uberis from a dairy's environment, bovine feces and milk," Veterinary Microbiology, vol. 109, no. 3-4, pp. 257-265, 2005.

[15] J. A. Leigh, S. A. Egan, P. N. Ward, T. R. Field, and T. J. Coffey, "Sortase anchored proteins ofStreptococcus uberisplay major roles in the pathogenesis of bovine mastitis in dairy cattle," Veterinary Research, vol. 41, no. 5, p. 63, 2010.

[16] R. Tassi, T. N. McNeilly, J. L. Fitzpatrick et al., "Strain-specific pathogenicity of putative host-adapted and nonadapted strains of Streptococcus uberis in dairy cattle," Journal of Dairy Science, vol. 96, no. 8, pp. 5129-5145, 2013.

[17] P. L. Davies, J. A. Leigh, A. J. Bradley, S. C. Archer, R. D. Emes, and M. J. Green, "Molecular epidemiology of Streptococcus uberis clinical mastitis in dairy herds: strain heterogeneity and transmission," Journal of Clinical Microbiology, vol. 54, no. 1, pp. 68-74, 2016.

[18] R. N. Zadoks, B. E. Gillespie, H. W. Barkema, O. C. Sampimon, S. P. Oliver, and Y. H. Schukken, "Clinical, epidemiological and molecular characteristics of Streptococcus uberis infections in dairy herds," Epidemiology and Infection, vol. 130, no. 2, pp. 335-349, 2003.

[19] J. Hogan, R. Gonzales, R. Harmon et al., Laboratory Handbook on Bovine Mastitis, National Mastitis Council, Madison, WI, USA, 1999.

[20] A. Capurro, K. Artursson, K. Waller, B. Bengtsson, H. Ericssonunnerstad, and A. Aspan, "Comparison of a commercialized phenotyping system, antimicrobial susceptibility testing, and tuf gene sequence-based genotyping for species-level identification of coagulase-negative staphylococci isolated from cases of bovine mastitis," Veterinary Microbiology, vol. 134, no. 3-4, pp. 327-333, 2009. 
[21] L. Odierno, L. Calvinho, P. Traverssa, M. Lasagno, C. Bogni, and E. Reinoso, "Conventional identification of Streptococcus uberis isolated from bovine mastitis in Argentinean dairy herds," Journal of Dairy Science, vol. 89, no. 10, pp. 3886-3890, 2006.

[22] P. Phuektes, P. D. Mansell, and G. F. Browning, "Multiplex polymerase chain reaction assay for simultaneous detection of Staphylococcus aureus and streptococcal causes of bovine mastitis," Journal of Dairy Science, vol. 84, no. 5, pp. 1140-1148, 2001.

[23] B. R. Shome, S. Das Mitra, M. Bhuvana et al., "Multiplex PCR assay for species identification of bovine mastitis pathogens," Journal of Applied Microbiology, vol. 111, no. 6, pp. 1349-1356, 2011.

[24] R. G. M. Olde Riekerink, H. W. Barkema, D. F. Kelton, and D. T. Scholl, "Incidence rate of clinical mastitis on Canadian dairy farms," Journal of Dairy Science, vol. 91, no. 4, pp. 1366-1377, 2008.

[25] B. Cressier and N. Bissonnette, "Assessment of an extraction protocol to detect the major mastitis-causing pathogens in bovine milk," Journal of Dairy Science, vol. 94, no. 5, pp. 2171-2184, 2011.

[26] S. Taponen, L. Salmikivi, H. Simojoki, M. T. Koskinen, and S. Pyörälä, "Real-time polymerase chain reaction-based identification of bacteria in milk samples from bovine clinical mastitis with no growth in conventional culturing," Journal of Dairy Science, vol. 92, no. 6, pp. 2610-2617, 2009.

[27] M. T. Koskinen, G. J. Wellenberg, O. C. Sampimon et al., "Field comparison of real-time polymerase chain reaction and bacterial culture for identification of bovine mastitis bacteria," Journal of Dairy Science, vol. 93, no. 12, pp. 5707-5715, 2010.

[28] N. M. Steele, J. H. Williamson, R. Thresher, R. A. Laven, and J. E. Hillerton, "Evaluating a commercial PCR assay against bacterial culture for diagnosing Streptococcus uberis and Staphylococcus aureus throughout lactation," Journal of Dairy Science, vol. 100, no. 5, pp. 3816-3824, 2017.

[29] J. Alber, A. El-Sayed, C. Lammler, A. A. Hassan, and M. Zschock, "Polymerase chain reaction mediated identification of Streptococcus uberis and Streptococcus parauberis using species-specific sequences of the genes encoding superoxide dismutase A and chaperonin $60 *$," Journal of Veterinary Medicine Series B, vol. 51, no. 4, pp. 180-184, 2004.

[30] B. E. Gillespie and S. P. Oliver, "Simultaneous detection of mastitis pathogens, Staphylococcus aureus, Streptococcus uberis, and Streptococcus agalactiae by multiplex real-time polymerase chain reaction," Journal of Dairy Science, vol. 88, no. 10, pp. 3510-3518, 2005.

[31] P. Cremonesi, B. Castiglioni, G. Malferrari et al., “Technical note: improved method for rapid DNA extraction of mastitis pathogens directly from milk," Journal of Dairy Science, vol. 89, no. 1, pp. 163-169, 2006.

[32] I. G. Wilson, "Inhibition and facilitation of nucleic acid amplification," Applied and Environmental Microbiology, vol. 63, no. 10, pp. 3741-3751, 1997.

[33] N. Peñafiel, D. M. Flores, J. Rivero De Aguilar, J. M. Guayasamin, and E. Bonaccorso, "A cost-effective protocol for total DNA isolation from animal tissue," Neotropical Biodiversity, vol. 5, no. 1, pp. 69-74, 2019.

[34] L. M. Schiebelhut, S. S. Abboud, L. E. Gómez Daglio, H. F. Swift, and M. N. Dawson, "A comparison of DNA extraction methods for high-throughput DNA analyses," Molecular Ecology Resources, vol. 17, no. 4, pp. 721-729, 2017.

[35] M. Hossain, S. A. Egan, and T. Coffey, et al., Virulence related sequences; insights provided by comparative genomics of
Streptococcus uberis of differing virulence," BMC Genomics, vol. 16, p. 334, 2015.

[36] A. J. Bramley, "Variations in the susceptibility of lactating and non-lactating bovine udders to infection when infused with Escherichia coli," Journal of Dairy Research, vol. 43, no. 2, pp. 205-211, 1976.

[37] A. J. Bramley, A. H. Patel, M. O’Reilly, R. Foster, and T. J. Foster, "Roles of alpha-toxin and beta-toxin in virulence of Staphylococcus aureus for the mouse mammary gland," Infection and Immunity, vol. 57, no. 8, pp. 2489-2494, 1989.

[38] H. Tettelin, "Complete genome sequence of a virulent isolate of Streptococcus pneumoniae," Science, vol. 293, no. 5529, pp. 498-506, 2001.

[39] P. N. Ward, M. T. Holden, J. A. Leigh et al., "Evidence for niche adaptation in the genome of the bovine pathogen Streptococcus uberis," BMC Genomics, vol. 10, no. 1, p. 54, 2009.

[40] S. F. Altschul, W. Gish, W. Miller, E. W. Myers, and D. J. Lipman, "Basic local alignment search tool," Journal of Molecular Biology, vol. 215, no. 3, pp. 403-410, 1990.

[41] T. J. Coffey, G. D. Pullinger, R. Urwin et al., "First insights into the evolution of Streptococcus uberis: a multilocus sequence typing scheme that enables investigation of its population biology," Applied and Environmental Microbiology, vol. 72, no. 2, pp. 1420-1428, 2006.

[42] K. A. Jolley and M. C. Maiden, "BIGSdb: Scalable analysis of bacterial genome variation at the population level," BMC Bioinformatics, vol. 11, p. 595, 2010.

[43] R. W. Bentley and J. A. Leigh, "Determination of $16 \mathrm{~S}$ ribosomal RNA gene copy number inStreptococcus uberis, S. agalactiae, S. dysgalactiaeandS. parauberis," FEMS Immunology \& Medical Microbiology, vol. 12, no. 1, pp. 1-7, 1995.

[44] S. A. Egan, P. N. Ward, M. Watson, T. R. Field, and J. A. Leigh, "Vru (Sub0144) controls expression of proven and putative virulence determinants and alters the ability of Streptococcus uberis to cause disease in dairy cattle," Microbiology, vol. 158, no. Pt 6, pp. 1581-1592, 2012.

[45] T. R. Field, P. N. Ward, L. H. Pedersen, and J. A. Leigh, "The hyaluronic acid capsule of Streptococcus uberis is not required for the development of infection and clinical mastitis," Infection and Immunity, vol. 71, no. 1, pp. 132-139, 2003.

[46] F. K. Neave, F. H. Dodd, R. G. Kingwill, and D. R. Westgarth, "Control of mastitis in the dairy herd by hygiene and management," Journal of Dairy Science, vol. 52, no. 5, pp. 696-707, 1969.

[47] M. Green and A. Bradley, "The changing face of mastitis control," Veterinary Record, vol. 173, no. 21, pp. 517-521, 2013.

[48] S. A. Egan, D. Kurian, P. N. Ward, L. Hunt, and J. A. Leigh, "Identification of sortase A (SrtA) substrates inStreptococcus uberis: evidence for an additional hexapeptide (lpxxxd) sorting motif," Journal of Proteome Research, vol. 9, no. 2, pp. 1088-1095, 2010.

[49] K. A. Jolley, J. E. Bray, and M. C. J. Maiden, "Open-access bacterial population genomics: BIGSdb software, the PubMLST.org website and their applications," Wellcome Open Research, vol. 3, p. 124, 2018.

[50] G. D. Pullinger, T. J. Coffey, M. C. Maiden, and J. A. Leigh, "Multilocus-sequence typing analysis reveals similar populations of Streptococcus uberis are responsible for bovine intramammary infections of short and long duration," Veterinary Microbiology, vol. 119, no. 2-4, pp. 194-204, 2007.

[51] L. Quigley, O. O’Sullivan, T. P. Beresford, R. Paul Ross, G. F. Fitzgerald, and P. D. Cotter, "A comparison of methods 
used to extract bacterial DNA from raw milk and raw milk cheese," Journal of Applied Microbiology, vol. 113, no. 1, pp. 96-105, 2012.

[52] P. Daly, T. Collier, and S. Doyle, "PCR-ELISA detection of Escherichia coli in milk," Letters in Applied Microbiology, vol. 34, no. 3, pp. 222-226, 2002.

[53] C. Romero and I. Lopez-Goñi, "Improved method for purification of bacterial DNA from bovine milk for detection of Brucella spp. by PCR," Applied and Environmental Microbiology, vol. 65, no. 8, pp. 3735-3737, 1999.

[54] L. Quigley, R. McCarthy, O. O'Sullivan et al., "The microbial content of raw and pasteurized cow milk as determined by molecular approaches," Journal of Dairy Science, vol. 96, no. 8, pp. 4928-4937, 2013.

[55] A. W. Hill and J. A. Leigh, "DNA fingerprinting of Streptococcus uberis: a useful tool for epidemiology of bovine mastitis," Epidemiology and Infection, vol. 103, no. 1, pp. 165-171, 1989.

[56] I. Fliss, E. Emond, R. E. Simard, and S. Pandian, "A rapid and efficient method of lysis of Listeria and other gram-positive bacteria using mutanolysin," Biotechniques, vol. 11, no. 4, pp. 456-457, 1991.

[57] S. Yuan, D. B. Cohen, J. Ravel, Z. Abdo, and L. J. Forney, "Evaluation of methods for the extraction and purification of DNA from the human microbiome," PLoS One, vol. 7, no. 3, Article ID e33865, 2012.

[58] U. Chaturvedi, A. K. Tiwari, B. Ratta et al., "Detection of canine adenoviral infections in urine and faeces by the polymerase chain reaction," Journal of Virological Methods, vol. 149, no. 2, pp. 260-263, 2008.

[59] A. J. Smith, P. N. Ward, T. R. Field, C. L. Jones, R. A. Lincoln, and J. A. Leigh, "MtuA, a lipoprotein receptor antigen from Streptococcus uberis, is responsible for acquisition of manganese during growth in milk and is essential for infection of the lactating bovine mammary gland," Infection and Immunity, vol. 71, no. 9, pp. 4842-4849, 2003. 